\title{
Durability of self-healing concrete
}

\author{
Nele De Belie ${ }^{1, *}$, Bjorn Van Belleghem ${ }^{1}$, Yusuf Çăgatay Erşan ${ }^{1,2,3}$, Kim Van Tittelboom ${ }^{1}$ \\ ${ }^{1}$ Magnel Laboratory for Concrete Research, Department of Structural Engineering, Faculty of Engineering and Architecture, \\ Ghent University, Technologiepark Zwijnaarde 60, B-9052 Ghent, Belgium \\ ${ }^{2}$ Centre for Microbial Ecology and Technology (CMET), Faculty of Bioscience Engineering, Ghent University, Coupure Links \\ 653, B-9000 Ghent, Belgium \\ ${ }^{3}$ Department of Environmental Engineering, Hacettepe University, Beytepe Campus, TR-06800, Ankara, Turkey
}

\begin{abstract}
Application of self-healing concrete reduces the need for expensive maintenance and repair actions. However, the durability of self-healing concrete has only been scarcely investigated. Here, recent results are presented regarding the resistance of self-healing concrete to chloride ingress. For self-healing concrete with macro-encapsulated polyurethane, chloride profiles and electron probe microanalysis indicated that this mechanism was efficient to reduce the chloride penetration into the crack and from the crack into the concrete matrix [1]. Furthermore, the corrosion behaviour of reinforced concrete specimens subjected to cyclic exposure with a $\mathrm{NaCl}$ solution was studied [2]. The electrochemical measurements indicated that autonomous crack healing could significantly reduce the corrosion in the propagation stage. No visual damage could be detected on the rebars after 44 weeks of exposure. On the contrary, cracked specimens without integrated self-healing mechanism, reached a state of active corrosion after 10 weeks of exposure and after 26 weeks clear pitting damage was observed on the rebars. While self-healing by encapsulated polyurethane is complete after one day, bacteria-based products take several weeks to heal a $300 \mu \mathrm{m}$ crack. Bacterial granules containing denitrifying cultures released nitrite as an intermediate metabolic product which protected the reinforcement during the crack healing process [3].
\end{abstract}

\section{Introduction}

The appearance of small cracks $(<300 \mu \mathrm{m}$ in width) in concrete is almost unavoidable, not necessarily causing a direct risk of collapse for the structure, but surely impairing its functionality, accelerating its degradation, and diminishing its service life and sustainability. The loss of performance results in the need for increased investments on maintenance and/or intensive repair/strengthening works. While concrete contains inherent self-healing properties, this autogenous healing mechanism is only efficient for small cracks. The phenomenon itself has been well studied, but the maximum healable crack sizes mentioned range between 10 to 100 , sometimes $150 \mu \mathrm{m}$ [4]. Autogenous healing is difficult to predict or rely on and only occurs in the presence of water. Therefore, concrete has been adapted to stimulate autogenous healing and in addition, mechanisms for autonomous healing have been invented. Even stimulated autogenous mechanisms (e.g. by introduction of superabsorbent polymers into the concrete) are generally limited to healing crack widths of about $100-150 \mu \mathrm{m}$, taking several weeks or even months to heal cracks completely, and heavily rely on the environmental conditions (mainly presence of water). In contrast, most autonomous self-healing mechanisms can heal cracks of $300 \mu \mathrm{m}$, even sometimes up to more than $1 \mathrm{~mm}$, and usually act faster (complete healing obtained in a time span of 1 day up to 3-4 weeks depending on the system). Autonomous healing agents include micro- and macro-encapsulated polymers or minerals, and bacteria based systems (encapsulated or not). For encapsulation, a whole range of shell materials have been investigated and tailored for use in cementitious matrices [4]. Researchers have made progress regarding changeable properties (flexible in fresh concrete to survive concrete mixing, while brittle in hardened concrete to release the contents at crack occurence) and improved bond with the cementitious matrix. The suggested optimum dosages usually range between $0.5 \%$ to $10 \%$ by weight of cement, to obtain sufficient healing in combination with a limited effect on mechanical properties of concrete. The long-term stability of encapsulated polymers remains a point of concern (especially due to the unavoidable permeability of the capsule shells). This is less problematic when encapsulating bacterial spores or mineral additives, since their "reactivity" with moisture penetrating through the shell is much lower.

A comprehensive review on self-healing concrete, aiming for damage management of structures, was recently compiled in a combined effort by COST CA15202 "SARCOS" members [4]. This review reveals the key challenge that the self-healing additions up-todate are produced at lab scale and self-healing efficiency is only shown at paste/mortar level. The rare existing demonstrators up-scaled in concrete structures often

* Corresponding author: nele.debelie@ugent.be 
show insufficient [5,6] or not yet proven [7, 8] selfhealing efficiency. Further, they lead to new questions, such as effect of variability in the design parameters and longevity of the embedded system [9]. One of the reasons for reduced efficiency after upscaling to concrete is the significant dilution of the additives when maintaining the dosage relative to cement weight; however, keeping the same dosage in proportion to the total volume, results mostly in an unacceptable strength decrease and high healing agent costs. Another challenge mentioned by the cited review paper is that the durability of self-healing concrete elements when exposed to, for instance, chlorides has only been scarcely investigated. No long-term durability results of self-healing concrete are available, and even results for accelerated durability testing in lab conditions are scarce. Mostly, durability is assessed indirectly through parameters such as gas and water permeability, surface resistivity and capillary absorption. Although presently more than 200 studies reported on improved durability aspects of concrete due to bacteria-mediated limestone formation, virtually all are based on short-term laboratory studies with indirect indicators. It is suggested that further research should focus on durability of the healed structures e.g. resistance to chloride diffusion and carbonation, corrosion, freeze/thaw, salt crystallization, etc. [4].

\section{Literature on durability of self-healing concrete}

Limited studies are available on durability of selfhealing concrete. Mostly, durability is linked to indirect indicators like water absorption or water permeability. The few articles that treat actual durability mostly focus on chloride ingress and a few on actual reinforcement corrosion.

\subsection{Chloride ingress in lab-scale specimens}

In our previous studies $[10,11]$, capsules containing polyurethane (PU) prepolymers were embedded in the concrete to release their content when cracks appear. The resistance to chloride penetration of autonomously healed mortar was evaluated experimentally by using the NT Build 443 diffusion test. At the age of 28 days, after saturation in a $4 \mathrm{~g} / 1 \mathrm{Ca}(\mathrm{OH})_{2}$ solution for 7 days, the specimens were placed in a closed container with a 165 $\mathrm{g} / \mathrm{l} \mathrm{NaCl}$ solution. In cracked mortar, the chloride diffusion coefficients in the zone immediately around the crack significantly increased compared to uncracked mortar. There was a limited effect of the crack width for cracks of $100 \mu \mathrm{m}$ to $300 \mu \mathrm{m}$ ), in which case the calculated service life decreased from 103 to 23 years (about 80\%). Autonomous crack healing had a beneficial influence on the resistance against chloride diffusion. However, for about one third of the cracks the healing mechanism failed, probably due to shifting of the capsules, excessive capillary forces in the capsules, etc. Nevertheless, the service life of autonomously healed structures by means of encapsulated polyurethane increased on average by about $100 \%$ compared to cracked structures, e.g. for self-healed cracks of $200 \mu \mathrm{m}$ a service life of 44 years was calculated based on the mean apparent diffusion coefficient. However, there was a lot of variability depending on the proper functioning of the healing mechanism. If the healing mechanism works efficiently, the crack is sealed well and almost no chlorides will penetrate into the crack, resulting in a predicted service life similar to sound structures.

Van Belleghem et al. [12] applied a similar system with macro-encapsulated PU, and after an accelerated diffusion test, the chloride concentration in the cracked zone was reduced by $75 \%$ or more as a result of the selfhealing action. As a result, the service life of steel reinforced self-healing concrete slabs in marine environments could amount to 60-94 years as opposed to only seven years for ordinary (cracked) concrete. Subsequent life cycle assessment calculations indicated important environmental benefits $(56 \%-75 \%)$ for the ten CML-IA (Center of Environmental Science of Leiden University-Impact Assessment) baseline impact indicators, which are mainly induced by the achievable service life extension.

Van den Heede et al. [13] proposed a modified chloride migration test based on the one prescribed in NT Build 492 to check self-healing concrete for marine environments. They used samples with an artificially induced crack (width: $0.3 \mathrm{~mm}$, depth: $25 \mathrm{~mm}$ ) in the bottom cast surface of concrete cylinders and have screened four macro-encapsulated polymer-based healing agents that way. A highly repeatable self-healing efficiency value of $100 \%$ could only be obtained for a commercial low-viscosity PU precursor.

The findings of Darquennes et al. [14] clearly indicated that autogenous healing at early age limits the chloride penetration and improves the structural durability, particularly for mixtures containing blastfurnace slag. Moreover, it was shown that the chloride migration test is an adequate method to monitor the selfhealing process. Finally, self-healed specimens could be simply regarded as specimens characterized by a smaller crack.

Sahmaran et al. [15] investigated the chloride transport properties of engineered cementitious composites (ECC) under combined mechanical and environmental loads. Immersion and salt ponding tests were conducted to determine chloride ion transport properties. Under high imposed bending deformation, the preloaded ECC beam specimens revealed microcracks less than $50 \mu \mathrm{m}$ and an effective diffusion coefficient significantly lower than that of the similarly preloaded reinforced mortar beam because of the tight crack width control. Through the formation of microcracks, a significant amount of self-healing was observed within the ECC cracks subjected to $\mathrm{NaCl}$ solution exposure.

$\mathrm{Li}$ and $\mathrm{Li}$ [16] investigated engineered cementitious composite's (ECC) durability in terms of maintaining its unique tensile characteristics under combined mechanical loading and aggressive chloride conditions. ECC specimens were preloaded to $0.5,1.0$, and $1.5 \%$ tensile strain levels; immersed in chloride solution for 30, 60, and 90 days; and reloaded until failure. This 
study revealed that the reloaded specimens retained multiple microcracking behaviour and tensile strain capacity greater than $2.5 \%$, while the average crack width increased from $50 \mu \mathrm{m}$ to $100 \mu \mathrm{m}$. Self-healing in ECC under chloride exposure was evident in terms of recovery of initial material stiffness and tensile strain capacity. Under severe marine environmental conditions, ECC remained durable.

Liu et al. [17] studied Engineered Cementitious Composites (ECC) with self-controlled tight microcracks and self-healing capacities under aggressive sulfate and chloride conditions. Resonant frequency (RF) and mechanical properties were determined for ECC specimens that were preloaded to $1 \%$ strain and exposed to sulfate and sulfate-chloride solutions. The performance of ECC was found not to be adversely affected by the aggressive solutions. Instead, self-healing of the microcracks was observed leading to partial recovery of the mechanical properties. It was also found that ECC tends to heal faster and more completely in sulfate solutions than in water.

Abro et al. [18, 19] used the rapid chloride ion migration test under the steady-state regime to assess the efficiency of self-healing of cracked mortar containing crystalline and expansive admixtures. The target crack widths were achieved by splitting cylindrical specimens into two pieces and reassembling them by a steel band with silicon tapes of required thickness attached between them on both edges. They suggested to choose a high potential $(36 \mathrm{~V})$ for the steady-state migration test to minimize the test duration (to 24-36 h) because otherwise the ongoing self-healing would affect the measurements. The self-healing capacity with respect to resistance to chloride penetration could be evaluated with this test, and an index for the recovery of resistance to chloride penetration due to self-healing could be defined by using the rate of chloride ions that pass through the crack. The diffusion coefficients obtained increased almost linearly in proportion to the crack width. For larger crack widths, they found that the mixture incorporating calcium sulfoaluminate as an expansive admixture and bentonite as a swelling agent, together with a crystalline admixture including disodium carbonate and organic calcium ions, showed better self-healing performance than the mixture incorporating only the crystalline admixture. Also, depending on the types of self-healing techniques, it was noted that there is a limit in the crack width that can be healed.

Van Mullem et al. [20] compared the chloride ingress in cracked mortar with and without superabsorbent polymers (SAP). The specimens were saturated in a chloride solution during 1 or 5 weeks after which the chloride ingress could be visualised using silver nitrate. The specimens, which were healed prior to chloride immersion, had a significantly lower chloride ingress. The SAPs were able to delay the chloride ingress, as well as limit the influence of the crack on the chloride ingress.

Asensio et al. [21] carried out an experimental campaign, involving the study of 342 samples, half of which contained a crystalline admixture. An enhanced recovery of strength and an improved crack sealing ability were observed for samples containing the healing agent.

Azarsa et al. [22] presented results on the influence of crystalline admixtures on the strength, self-healing, and durability characteristics of concrete, using the rapid chloride permeability (RCP), surface/bulk electrical resistivity and water permeability test, self-healing test, compressive strength test and salt ponding test. The water permeability coefficient decreased by three times whereas the self-healing ratio increased by a higher rate by adding crystalline admixtures to the concrete mix.

Liu et al. [23] studied the mechanism and selfhealing kinetics of cement paste with chelating agent in marine environment. They found that cracks with an initial width of $400 \mu \mathrm{m}$ could heal completely within 2 days. Brucite and calcite were the main minerals of the reaction products of self-healing in cement paste with chelating agent submersed in seawater, and their percentage in the reaction products of self-healing was about $60 \%$ and $30 \%$, respectively.

Perez et al. [24] investigated the durability of selfhealing micro-concrete by freeze-thaw cycles and salt spray test. The ultra-high-strength reinforced microconcrete contained an autonomous healing mechanism based on the reaction of an epoxy compound enclosed within silica microcapsules and amine functionalised silica nanoparticles distributed within the cementitious matrix. The results of capillary water absorption tests, complemented by electron microscopy analysis, confirmed the enhanced durability of the autonomously healed material in both the freeze-thaw and the salt spray tests, as compared to the reference micro-concrete.

Palin et al. [25, 26] studied beads consisting of calcium alginate encapsulated bacterial spores and mineral precursor compounds for application in lowtemperature marine environments. The material displayed an excellent crack-healing capacity, reducing the permeability of $0.4 \mathrm{~mm}$-wide cracks by $95 \%$, and 0.6 mm-wide cracks by $93 \%$ following 56 days of submersion in artificial seawater at $8{ }^{\circ} \mathrm{C}$. Healing of the cracks was attributed to autogenous precipitation, autonomous bead swelling, magnesium-based mineral precipitation, and bacteria-induced calcium-based mineral precipitation in and on the surface of the bacteria-based beads.

\subsection{Chloride ingress in real-scale specimens}

Araujo et al. [27] carried out real-scale tests on concrete beams of $2.5 \mathrm{~m} \times 0.40 \mathrm{~m} \times 0.20 \mathrm{~m}$ reinforced with four ribbed steel bars $(\varnothing=10 \mathrm{~mm})$. Poly(methyl methacrylate) and glass capsules were used to encapsulate the healing agent. The beams were positioned slightly tilted with the cracks in the upper surface and a $3 \mathrm{wt} \% \mathrm{NaCl}$ solution was flowing over the beams for 1 day per week, during 6 consecutive weeks. The tests revealed that the resistance of cracked concrete against chloride could be increased when incorporating self-healing properties. Most sampled cracks were completely healed, with chloride ingress being similar to uncracked concrete. 


\subsection{Corrosion monitoring of embedded steel reinforcement}

Van Tittelboom et al. [28] carried out an accelerated corrosion test on mortar samples with embedded reinforcement bars, which showed that the presence of cracks accelerates the onset and propagation of corrosion at the interface between the rebar and the cementitious matrix. They highly increased the corrosion rate by using a high chloride concentration and by applying a potential difference of $15 \mathrm{~V}$ over the length of the rebar. They found that both manual crack healing and autonomous healing with polyurethane delayed the onset and propagation of corrosion. The difference in corrosion behaviour was proven by visual evaluation of the rebar surface and by X-ray radiographic analysis.

\section{Chloride ingress in cracked self- healing concrete with macro- encapsulated polyurethane}

Our recent research focused on an accurate measurement of (perpendicular-to-crack) chloride ingress in case of autonomous crack healing by encapsulated polyurethane [1]. Chloride profiles were obtained by grinding followed by potentiometric titration and by Electron Probe Micro Analysis (EPMA).

Autonomous crack healing was achieved by embedding glass capsules (length $35 \mathrm{~mm}$, internal diameter 3.00 $\mathrm{mm}$, wall thickness $0.175 \mathrm{~mm}$ ) filled with a polyurethane (PU) precursor in the concrete matrix. At the moment of crack appearance, the polyurethane precursor is released from the capsules and polymerizes within 24 to 48 hours when it comes in contact with moisture in the concrete matrix. Artificial standardized cracks were created in cylindrical concrete specimens $(\varnothing=100 \mathrm{~mm} ; \mathrm{h}=50$ $\mathrm{mm}$ ) by introducing thin brass plates with a thickness of $300 \mu \mathrm{m}$ into the fresh concrete, which were removed after $28 \mathrm{~d}$ of curing at $20^{\circ} \mathrm{C}$ and a relative humidity (RH) of $>95 \%$. The removal of the plates in the specimens with the autonomous healing mechanism caused breakage of the capsules which were mounted through holes in the brass plates. After $48 \mathrm{~h}$ curing of the PU, the specimens were coated with an epoxy coating on all sides except the test surface. Three traditional and three self-healing specimens were subjected to an accelerated chloride diffusion test according to NT Build 443 (immersion in a $165 \mathrm{~g} / \mathrm{l} \mathrm{NaCl}$ solution at $20^{\circ} \mathrm{C}$ ) for a total period of 605 days. Then, the specimens were split along the direction of the crack. One half was used for profile grinding after which the total chloride content of the powders was determined through an acid-soluble extraction in a nitric acid solution followed by a titration against silver nitrate. The other half was split again and a piece of $50 \mathrm{~mm}$ x $40 \mathrm{~mm}$ was polished, embedded in an epoxy resin and analysed by EPMA (pixel size of 50 $\mu \mathrm{m})$. After a calibration procedure [30], the chloride contents can be obtained from the EPMA analysis.

In the traditional concrete samples, a very high chloride concentration was noticed at the crack wall
(1.39 $\mathrm{m} \%$ per concrete mass near the crack mouth and $1.1 \mathrm{~m} \%$ deeper down in the crack). Deeper down in the crack, the influence of the crack caused increased chloride contents until 14 to $18 \mathrm{~mm}$ away from the crack wall. Self-healing specimens showed a much smaller increase in chloride content near the crack wall, especially deeper down in the crack, where the chloride concentration at the crack wall was only $0.27 \mathrm{~m} \%$. Furthermore, an increased chloride concentration was only seen up to $4 \mathrm{~mm}$ away from the crack near the crack mouth, while in the deepest zone of the crack, the influence of the crack could be seen until a distance of 8 $\mathrm{mm}$ from the crack surface. Overall, at all positions, the measured chloride contents were much below those measured in the traditional concrete. These conclusions can also be clearly drawn from the chloride analysis done by EPMA. The healed specimens show much less chloride ingress along the crack than the traditional cracked specimens (Fig. 1). Therefore, it is clear that self-healing with macro-encapsulated polyurethane will reduce the chloride concentrations in the crack and reduce the perpendicular-to-crack chloride penetration.
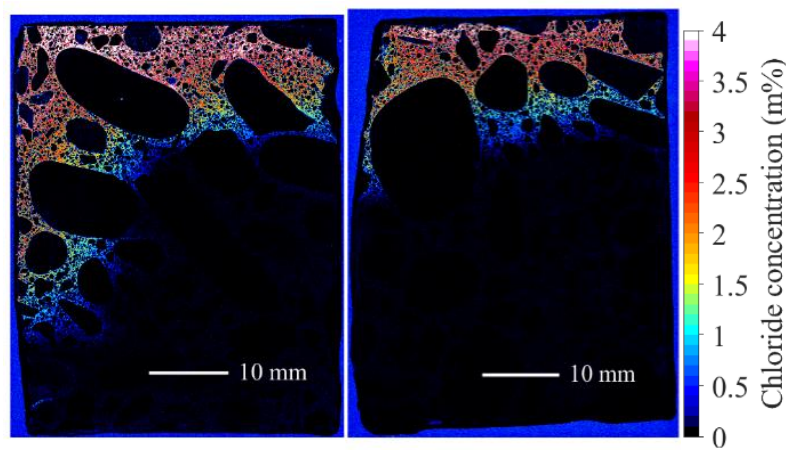

Fig. 1. Example of EPMA maps showing chloride penetration for cracked specimens of traditional concrete (left) and cracked specimens of self-healing concrete (right). The crack is at the left-hand side of the images. Redrafted after [1].

\section{Corrosion of steel reinforcement in self-healing concrete with macro- encapsulated polyurethane}

Subsequently, the corrosion behaviour of reinforced concrete specimens subjected to cyclic exposure with a $\mathrm{NaCl}$ solution was studied [2]. Steel reinforced concrete prisms with dimensions of $120 \mathrm{~mm} \times 120 \mathrm{~mm} \times 500 \mathrm{~mm}$ were made for corrosion monitoring, based on a design by Kessler et al. [29].

The steel reinforcement (BE500S) consisted of two parts which were electrically separated from each other: a centrally located steel bar anode $(\varnothing=10 \mathrm{~mm}$, length $250 \mathrm{~mm}$, concrete cover $25 \mathrm{~mm}$ ) and two cathodic reinforcement cages made by four longitudinal rebars $(\varnothing=8 \mathrm{~mm})$ and five stirrups $(\varnothing=6 \mathrm{~mm})$, connected by an insulated copper wire. Both the anodic and cathodic part of the reinforcement were connected to the exterior by means of a copper wire. The self-healing specimens contained two layers of six capsules with low $(200 \mathrm{mPas}$ at $\left.25^{\circ} \mathrm{C}\right)$ or high viscosity $\mathrm{PU}\left(6700 \mathrm{mPas}\right.$ at $\left.25^{\circ} \mathrm{C}\right)$ in the 
centre of the concrete prisms, one layer above and one layer below the anodic rebar.

After $28 \mathrm{~d}$ curing at $20^{\circ} \mathrm{C}$ and $>95 \% \mathrm{RH}$, a crack of around $300 \mu \mathrm{m}$ was created by means of a three-point bending test. Capsule breakage resulted in release of the PU precursor inside the crack and $48 \mathrm{~h}$ of storage at 20 ${ }^{\circ} \mathrm{C}$ and $60 \% \mathrm{RH}$ allowed the PU to polymerize. The concrete specimens were then exposed to 44 cycles of consecutively 1 day with $33 \mathrm{~g} / \mathrm{l} \mathrm{NaCl}$ solution in the cracked area (and $1.15 \mathrm{~g} / \mathrm{l} \mathrm{Ca}(\mathrm{OH})_{2}$ solution further away from the crack), followed by a 6 day dry period, as described in [2]. The macro-cell corrosion current between anode and cathode ( $I_{\text {macro }}$ ) was measured approximately once every hour with a low resistance ammeter. Weekly electrochemical measurements were performed at the end of the wet period with a potentiostat (Gamry Interface 1000E) using an internal $\mathrm{Ag} / \mathrm{AgCl}$ reference electrode that was embedded in the concrete near the location of the anodic rebar, or with an external saturated calomel reference electrode (SCE) placed in the $\mathrm{NaCl}$ solution above the middle of the prisms. The corrosion potential $\left(\mathrm{E}_{\mathrm{corr}}\right)$ was measured while anode and cathode were connected. Subsequently the anode and cathode were disconnected and after depolarization (16 h), the open circuit potential (OCP) of anode and cathode was measured and the corresponding driving potential $(\Delta \mathrm{E})$ was calculated as the difference of these potentials. Thereafter, the linear anodic and cathodic polarization resistance, $R_{P, A}$ and $R_{P, C}$ respectively, were measured. Finally, electrochemical impedance spectroscopy (EIS) was performed to determine the development of the concrete resistance $\left(\mathrm{R}_{\mathrm{E}}\right)$. When all measurements were performed, the anode and cathode were connected again. All electrochemical measurements were performed weekly during the first 12 weeks of the wet-dry cycles and thereafter every two to four weeks. Only the macro-cell corrosion current and corrosion potential will be discussed here (Figure 2), more information can be found in [30].

The uncracked samples showed a non-active state of corrosion along the whole exposure period. No macrocell corrosion current was detected and the corrosion potential was nearly constant at values of -70 to $+80 \mathrm{mV}$ versus $\mathrm{Ag} / \mathrm{AgCl}$. The cracked samples showed clear evidence of corrosion initiation within the first three weeks of exposure to $\mathrm{NaCl}$ solution: there is a steep rise in the macrocell corrosion current and a drop of the corrosion potential ranging from 120 to $280 \mathrm{mV}$. Generally, the corrosion behaviour of the self-healing samples with high viscosity PU (PU_HV_CAPS) was very similar to the corrosion behaviour of the cracked samples. However, the self-healing samples with low viscosity PU (PU_LV_CAPS) behaved more closely to the uncracked samples. The macro-cell corrosion current was negligibly small and the anodic polarization resistance was comparable to the values found for the uncracked samples. The mean rate of volumetric loss of steel only amounted to $0.042 \mathrm{~mm}^{3} /$ week, which was 14 times lower than what was found for the untreated cracked samples. The rebars also showed no or very limited signs of damage due to corrosion after visual inspection.

\section{Corrosion of steel reinforcement in self-healing concrete with bacterial granules}

Self-healing by encapsulated polyurethane can proceed quickly due to the fast mechanism of crack filling and polyurethane curing. On the other hand, self-healing through biominerals produced by bacteria takes more time.
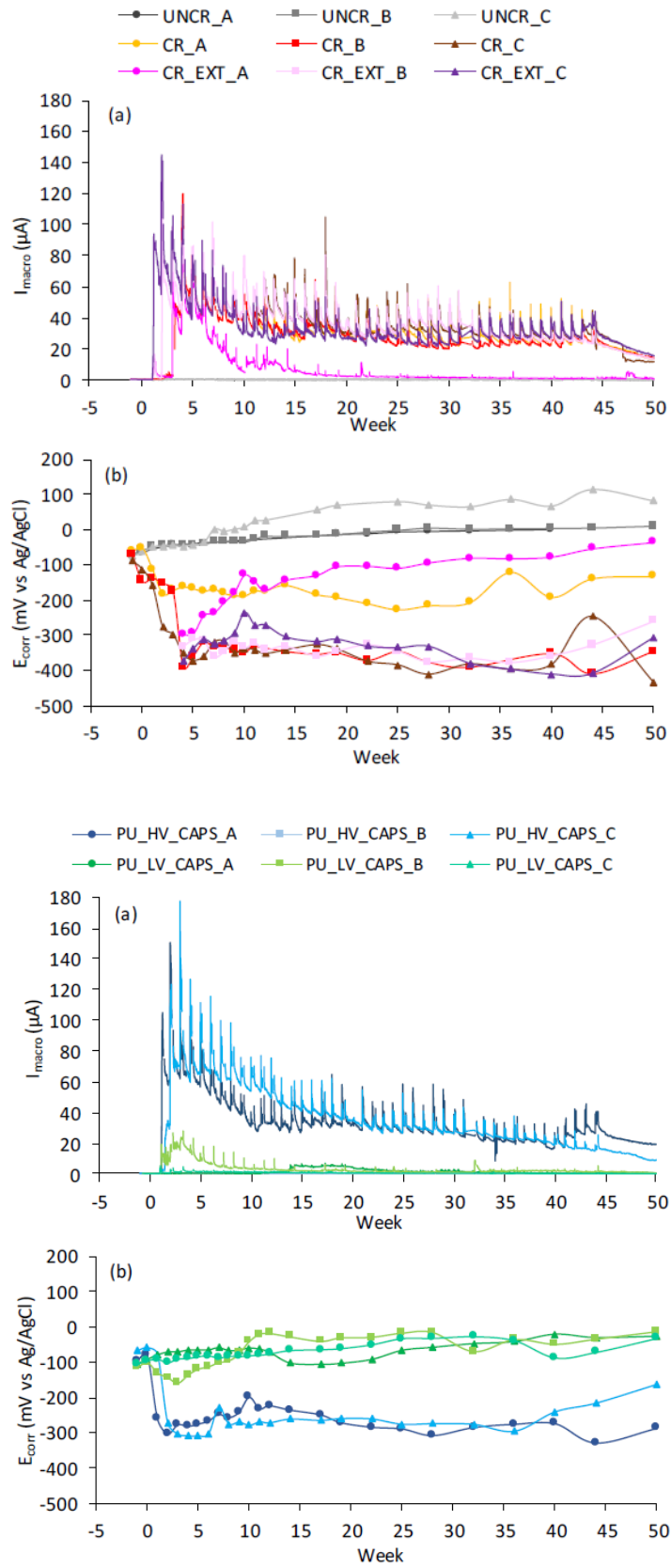

Fig. 2. The electrochemical corrosion parameters macro-cell corrosion current and corrosion potential for uncracked (UNCR) and cracked (CR) samples (top) and for self-healing samples with high (HV) and low (LV) viscosity PU (bottom). Redrafted after [30].

Complete healing of a $300 \mu \mathrm{m}$ crack will generally take several weeks. Therefore, it was investigated whether the latter approach can avoid corrosion of cracked concrete in a chloride containing environment. Self-protected bacterial granules containing either ureolytic or 
denitrifying cultures were integrated in mortar specimens containing a steel rebar. Denitrification can be advantageous when the necessary nutrients are considered. Yeast extract, urea, calcium lactate and calcium glutamate used for urea hydrolysis, are organic compounds which may negatively affect concrete properties. In the case of denitrification, commercial concrete admixtures such as calcium formate and calcium nitrate can serve as nutrient source for $\mathrm{NO}_{3}{ }^{-}$ reducing bacteria without any negative effect. Selfhealing strategies using ureolytic bacteria lack the preventive action to avoid exposure of the steel surface to corrosive substances during the healing period. However, recent proof-of-concept studies show that it is possible to achieve nitrite production and hence corrosion inhibition by using $\mathrm{NO}_{3}$ - reducing bacteria [31].

Microbial $\mathrm{NO}_{3}{ }^{-}$reduction was investigated by using a non-axenic self-protected $\mathrm{NO}_{3}{ }^{-}$reducing culture called ACDC, produced as described in [3]. In corrosion experiments, as a control culture, a self-protected nonaxenic ureolytic culture was used (CERUP, produced by Avecom NV, Belgium), with an effect on mortar properties similar to ACDC, while it can induce crack sealing through urea hydrolysis. Admixtures of $\mathrm{Ca}(\mathrm{HCOO})_{2}$ and $\mathrm{Ca}\left(\mathrm{NO}_{3}\right)_{2}$ were used in the mortar with the ACDC, and $\mathrm{CO}\left(\mathrm{NH}_{2}\right)_{2}$ was used as a nutrient for the CERUP. A series of mortar specimens $(40 \mathrm{~mm} \times 40 \mathrm{~mm}$ $\times 160 \mathrm{~mm}$ ) was prepared according to EN 196-1, with an embedded central smooth steel rebar $(\varnothing=8 \mathrm{~mm})$. The microbial test mortar contained ACDC $(0.5 \% \mathrm{wt} / \mathrm{wt}$ cement), $\mathrm{Ca}\left(\mathrm{NO}_{3}\right)_{2}(3 \% \mathrm{wt} / \mathrm{wt}$ cement $)$ and $\mathrm{Ca}(\mathrm{HCOO})_{2}$ ( $2 \% \mathrm{wt} / \mathrm{wt}$ cement) in addition to the components present in plain mortar. The positive control mortar contained $\mathrm{NO}_{2}^{-}(1.6 \% \mathrm{wt} / \mathrm{wt}$ cement $)$ as a corrosion inhibitor in the form of $\mathrm{NaNO}_{2}(2.4 \% \mathrm{wt} / \mathrm{wt}$ cement $)$ and $\mathrm{Ca}(\mathrm{HCOO})_{2}$ ( $2 \% \mathrm{wt} / \mathrm{wt}$ cement). Abiotic control mortar contained the nutrients of the microbe-based test batch, $\mathrm{Ca}\left(\mathrm{NO}_{3}\right)_{2}(3 \%$ wt/wt cement) and $\mathrm{Ca}(\mathrm{HCOO})_{2}(2 \% \mathrm{wt} / \mathrm{wt}$ cement $)$. The microbial self-healing control mortar contained CERUP $\left(0.5 \% \mathrm{wt} / \mathrm{wt}\right.$ cement) and $\mathrm{CO}\left(\mathrm{NH}_{2}\right)_{2}(5 \% \mathrm{wt} / \mathrm{wt}$ cement $)$. The prepared mortar specimens were cured at a temperature of $20^{\circ} \mathrm{C}$ and a $\mathrm{RH}$ of $>90 \%$ for 28 days. Artificial cracks were formed after $24 \mathrm{~h}$ curing according to the procedure described previously [32], by using $300 \mu \mathrm{m}$-thick brass plates with a semi-circular notch $(\varnothing$ $=8 \mathrm{~mm}$ ) against which the smooth rebar was positioned. At the end of the 28-days curing period, cracked and uncracked pieces $(38 \mathrm{~mm} \times 40 \mathrm{~mm} \times 15 \mathrm{~mm})$ were sawn from the prisms. The widths of the artificially created cracks were measured with a stereomicroscope after creation and at the end of the 28-days and 120-days experimental periods. Corrosion testing was done by placing conductive, insulated copper wires in contact with one end of the steel rebar to create an electrical connection with the data logging system. The cracked surfaces of the specimens $(40 \mathrm{~mm} \times 15 \mathrm{~mm})$ were immersed in $0.5 \mathrm{M} \mathrm{Cl}^{-}$solution and kept in contact with the solution for 28 and 120 days. Throughout the experiments, the dissolved oxygen concentration in the bulk solutions was $7.3 \pm 0.2 \mathrm{mg} / \mathrm{L}$ and the $\mathrm{pH}$ was $9.1 \pm$ 0.1 . The electrochemical corrosion potential was monitored by recording the open circuit potential (OCP) versus a reference saturated calomel electrode (SCE) for 120 days. All data (versus reference SCE) were converted to values versus the standard hydrogen electrode (SHE), on the basis of the given equilibrium potentials. The obtained data were compared with the limit OCP value ( $-250 \mathrm{mV}$ vs SHE). At the end of the experiments, the steel rebars were taken out of the tested specimens, cleaned and weighed.

The first 28 days of the $\mathrm{Cl}^{-}$exposure experiment can be defined as the pre-sealing period and half of the specimens ( 3 of each series) were used to determine the corrosion behaviour of the rebars at that time. The other half of the mortar specimens were monitored further in $\mathrm{Cl}^{-}$solution, until day 120 (combination of pre-sealing and post-sealing exposure to salt solution).

Among the cracked mortar specimens, only bacteriabased mortars showed complete healing of the cracks in a short period of time. Mortar containing ACDC granules showed complete crack closure in 28 days similar to the self-healing control mortar containing ureolytic bacteria. The healing material was stable in both mortars until the end of the experiment.

The OCP results revealed that rebar corrosion initiated in the cracked plain mortar after 16 days exposure to $\mathrm{Cl}^{-}$solution (significant drop below -250 $\mathrm{mV}$ ) whereas it took 44 days for the rebar in the abiotic control batch (Fig. 3). In both cases, after corrosion initiation, the OCP values dropped sharply below the critical value $(-250 \mathrm{mV})$. The rebars in the self-healing control started to corrode on day 28. Although the crack was completely sealed in 28 days, the rebar protection performance of the self-healing control did not become any better than that of the other negative controls (i.e. abiotic control and plain mortar) during the post-sealing period between 28 and 120 days. The rebar embedded in the mortar specimens containing ACDC always showed OCP values higher than $-250 \mathrm{mV}$ throughout the 120 days experimental period, similar to those embedded in the positive-control mortars containing $\mathrm{NO}_{2}^{-}$. In both types, no sharp decrease occurred in the OCP value throughout the test. In addition, the mass losses measured from the steel reinforcement showed that ACDC containing mortar could reach the rebar protection performance of uncracked mortar in both preand post-sealing periods, similar to the positive control. For the rebars embedded in ACDC containing mortars, the mass loss corresponded to $50 \%$ of the loss recorded for negative control specimens. When corrosion inhibition occurred, the rebars lost less than $2 \%$ of the total material (average rebar mass $5.5 \pm 0.2 \mathrm{~g}, n=30$ ) at the end of 120 days exposure to salt solution. More information can be found in [3]. 


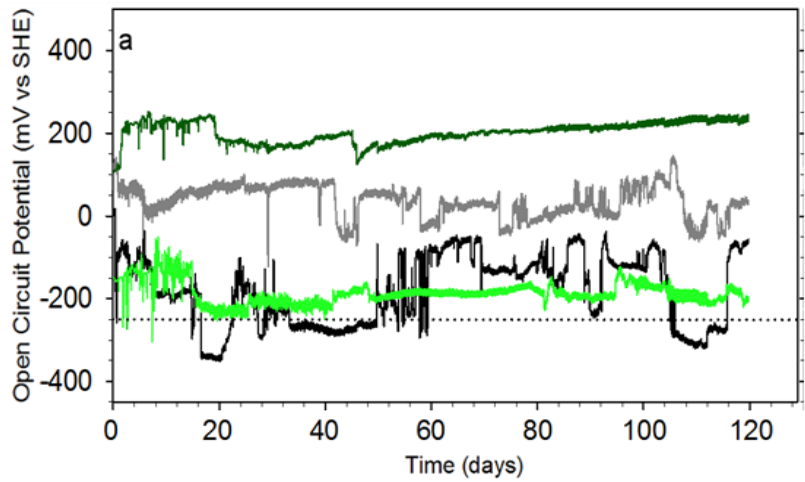

$$
\begin{aligned}
& \text { Uncracked plain mortar } \\
& \text { - Cracked plain mortar } \\
& \text { Uncracked positive control } \\
& \text { Cracked positive control }
\end{aligned}
$$

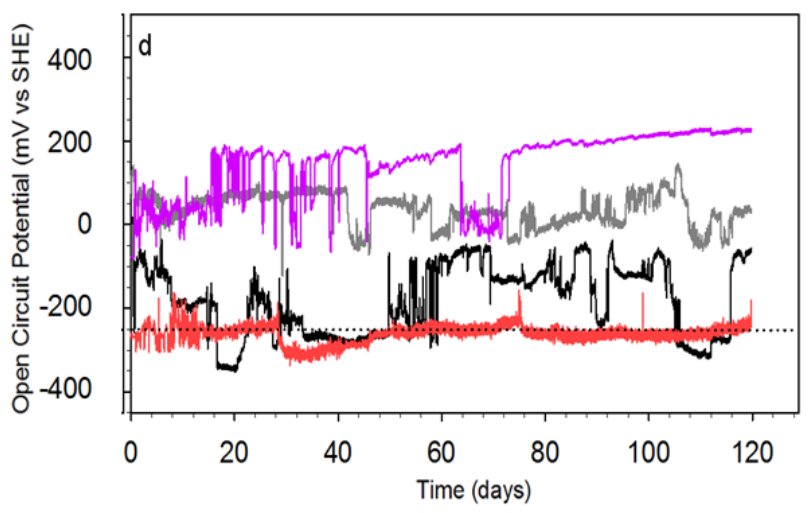

- Uncracked microbe-based self-healing control with 0.5\% CERUP - Cracked microbe-based self-healing control with $0.5 \%$ CERUP

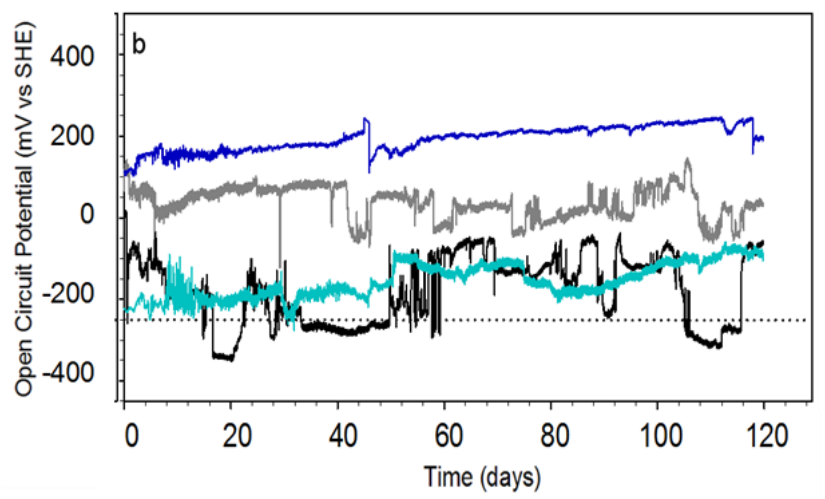

\section{- Uncracked microbe-based mortar with 0.5\% ACDC} - Cracked microbe-based mortar with 0.5\% ACDC

Fig. 3. OCP versus SHE for uncracked and cracked normal mortar (all graphs), uncracked and cracked positive control containing chemical nitrite as corrosion inhibitor (top), uncracked and cracked self-healing mortar with ureolytic CERUP (middle), uncracked and cracked self-healing mortar with denitrifying ACDC (bottom). Redrafted after [3].

\section{Conclusions}

Self-healing concrete has been the topic of increasing research attention over the last decade. Several methodologies to realize self-healing have been developed, but their effect on concrete durability and service life has only been scarcely investigated. Mostly, durability is assessed indirectly through parameters such as water absorption or permeability of cracked and healed concrete. Nevertheless, more recently several researchers also started investigating chloride ingress and corrosion of embedded reinforcement steel. In the current article, this literature is summarized. Furthermore, some highlights of our own recent findings are presented, regarding durability of self-healing concrete with macroencapsulated polyurethane on the one hand, and with granulated denitrifying bacteria on the other hand.

Through analysis of specimens that had been submersed in chloride solution, by titration on drilled powders and EPMA, it was shown that self-healing with macro-encapsulated polyurethane will reduce the chloride concentrations in the crack and reduce the perpendicular-to-crack chloride penetration. Furthermore, electrochemical measurements on reinforced prisms indicated that the corrosion behaviour of the self-healing samples with low viscosity PU behaved very similar to the uncracked samples. The macro-cell corrosion current was negligible and the anodic polarization resistance was comparable to the values found for the uncracked samples. The volumetric loss of steel only amounted to $0.042 \mathrm{~mm}^{3} /$ week, which was 14 times lower than what was found for the untreated cracked samples.

Self-healing implies that a crack formed in a concrete structure will activate a healing mechanism, leading to crack filling, regain of liquid tightness and/or mechanical properties. However, complete healing takes time, ranging from several hours (for encapsulated polymers) to several weeks (for encapsulated mineral or crystalline additions and bacteria). In this time span, corrosion of reinforcement steel can be initiated. In a simple corrosion test, it was shown that in the case of bacteriabased healing; only the denitrifying cultures were able to protect the reinforcement as efficiently as if the specimens contained a chemical nitrite based inhibitor. This can be ascribed to the release of nitrite as an intermediate metabolic product by the bacterial granules with a denitrifying core. In cracked mortar, rebar corrosion initiated after 16 days exposure to $0.5 \mathrm{M} \mathrm{Cl}^{-}$ solution (drop of open circuit potential below $-250 \mathrm{mV}$ ). In the case of bacteria based self-healing using a ureolytic culture, corrosion continued as well, even though complete crack healing was seen after 4 weeks.

The proposed self-healing mechanisms will in future have to be tested for their efficiency in larger concrete elements and more realistic environmental conditions.

\section{Acknowledgements}

Part of the described research was performed in the framework of the ISHECO project (Impact of Self-Healing Engineered Materials on steel COrrosion of reinforced concrete) under the program SHE (Engineered Self-Healing materials). The research was funded by SIM (Strategic Initiative Materials in Flanders) and VLAIO (Flanders Innovation and 
Entrepreneurship). The financial support from the foundation for this study is gratefully acknowledged.

\section{References}

1. B. Van Belleghem, Y. Villagrán Zaccardi, P. Van Den Heede, K. Van Tittelboom, N. De Belie, Con Build Mat (to be published)

2. B. Van Belleghem, S. Kessler, P. Van Den Heede, K. Van Tittelboom, N. De Belie, Cem Con Res 113, 130-139 (2018)

3. Y.C. Erşan, K. Van Tittelboom, N. Boon, N. De Belie, Nature - Sci Rep 8, 14092 (2018)

4. N. De Belie et al., Adv Mat Int, 1800074 (2018)

5. K. Paine et al., RILEM pro123, 387-394 (2018)

6. M. Araujo et al., Cem Con Comp 89, 2602018 (2018)

7. N. De Belie N et al., SLD, Delft, 429-436 (2018)

8. R. Davies et al., Front Mat, 00051 (2018)

9. A. Kanellopoulos et al. Smart Mater Struct 26, 45025 (2017)

10. M. Maes, N. De Belie, N. Proc Concrete Solutions 6th Int. Conf. On Concrete Repair, CRC Press, Thessaloniki, 409-415 (2016)

11. M. Maes, K. Van Tittelboom, N. De Belie. Con build mat 71, 528-537 (2014).

12. B. Van Belleghem, P. Van den Heede, K. Van Tittelboom, N. De Belie. Materials 10, 5 (2017)

13. P. Van den Heede, B. Van Belleghem, M.A. Araujo, J. Feiteira, N. De Belie, N. Key Eng Mat 761, 152158 (2018)

14. A. Darquennes, K. Olivier, F. Benboudjema, R. Gagne. Con build mat, 113, 1017-1028 (2016).

15. M. Sahmaran, M. Li, V.C. Li. ACI mat J 6, 604-611 (2007)

16. M. Li, V.C. Li, ACI mat J 108, 333-340 (2011)

17. H.Z. Liu, Q. Zhang, C.S. Gu, H.Z. Su, V. Li. Con Build Mat 153, 984-956 (2017).

18. F.R. Abro, A.S. Buller, K.-M. Lee, S.Y. Jang. Materials 12, 1865 (2019)

19. F.R. Abro, K.S. Min, S.Y. Jang, K.-M. Lee, A.S. Buller. Proc. ICSHM, Yokohama (2019)

20. T. Van Mullem, R. Caspeele, N. De Belie. Proc. Concrete Solutions $7^{\text {th }}$ Int. Conf. on Concrete Repair, Cluj Napoca. MATEC Web of Conferences (2019)

21. E.C. Asensio, S. Rigamonti, E. Gastaldo, L. Ferrara. Proc. ICSHM, Yokohama (2019)

22. P. Azarsa, R. Gupta, A. Biparva. Cem Con Comp 99, 17-31 (2019).

23. H. Liu, X. Wang, X. Wu, H. Huang. Proc. ICSHM, Yokohama (2019)

24. G. Perez, J.L. Garcia Calvo, P. Carballosa, et al. Mag con res 23, 1231-1242 (2017)
25. D. Palin, V. Wiktor, H.M. Jonkers. Biomimetics 2 (3), 13 (2017)

26. D. Palin, V. Wiktor, H.M. Jonkers. Smart mat struct 25 (8), 084008 (2018)

27. M. Araújo, S. Chatrabhuti, S. Gurdebeke, N. Alderete, K. Van Tittelboom, J.-M. Raquez, V. Cnudde, S. Van Vlierberghe, N. De Belie, E. Gruyaert, Cem Con Comp 89, 260-271 (2018)

28. K. Van Tittelboom, B. Van Belleghem, M.N. Boone, L. Van Hoorebeke, N. De Belie. Adv Mat Int, 1701021 (2017)

29. S. Kessler, F. Hiemer, C. Gehlen, Beton- und Stahlbetonbau. 112, 198-206 (2017)

30. B. Van Belleghem, PhD, Ghent University (2018).

31. Y.C. Erşan, H. Verbruggen, I. De Graeve, W. Verstraete, N. De Belie, N. Boon, Cem Con Res 83, 19-30 (2016)

32. B. Van Belleghem et al. Con Build Mat 110, 154162 (2016) 